OPEN ACCESS

Edited by:

Artur Mayerhofer,

Ludwig Maximilian University of

Munich, Germany

Reviewed by:

Senthilkumar Palaniappan, Karpagam Academy of Higher

Education, India

Cristina Soriano-Úbeda,

Universidad de León, Spain

${ }^{*}$ Correspondence:

Chunjin Li

IIcjj@163.com

Xu Zhou

xzhou65@vip.sina.com

${ }^{\dagger}$ These authors share first authorship

Specialty section:

This article was submitted to

Reproduction,

a section of the journal

Frontiers in Endocrinology

Received: 03 August 2021

Accepted: 25 October 2021

Published: 19 November 2021

Citation:

Luo Y, Zhu Y, Basang W, Wang X,

Li C and Zhou X (2021) Roles of

Nitric Oxide in the Regulation of

Reproduction: A Review.

Front. Endocrinol. 12:752410.

doi: 10.3389/fendo.2021.752410

\section{Roles of Nitric Oxide in} the Regulation of Reproduction: A Review

\author{
Yuxin $\mathrm{Luo}^{1 \dagger}$, Yanbin $\mathrm{Zhu}^{2 \dagger}$, Wangdui Basang ${ }^{2 \dagger}$, Xin Wang ${ }^{1}$, Chunjin $\mathrm{Li}^{1 *}$ and Xu Zhou ${ }^{1 *}$ \\ ${ }^{1}$ College of Animal Science, Jilin University, Changchun, China, ${ }^{2}$ State Key Laboratory of Hulless Barley and Yak Germplasm \\ Resources and Genetic Improvement, Lhasa, China
}

Nitric oxide (NO) has attracted significant attention as a stellar molecule. Presently, the study of NO has penetrated every field of life science, and NO is widely distributed in various tissues and organs. This review demonstrates the importance of NO in both male and female reproductive processes in numerous ways, such as in neuromodulation, follicular and oocyte maturation, ovulation, corpus luteum degeneration, fertilization, implantation, pregnancy maintenance, labor and menstrual cycle regulation, spermatogenesis, sperm maturation, and reproduction. However, the mechanism of action of some $\mathrm{NO}$ is still unknown, and understanding its mechanism may contribute to the clinical treatment of some reproductive diseases.

Keywords: nitric oxide, reproduction, animals, female, male

\section{OVERVIEW OF NITRIC OXIDE}

Before the last century, NO was considered a simple inorganic molecule that is toxic to living organisms. In 1980, Furchgott and Lawadzki found that vascular endothelial cells can produce and release a vasodilating substance, an endothelial cell-derived relaxing factor. In 1987, studies by Palmer and others showed that NO is the vasodilating substance released by vascular endothelial cells, which can lower blood pressure, inhibit vascular smooth muscle cell proliferation, and inhibit platelet adhesion (1). NO has received increasing attention in various fields of life science and has become a research hotspot in biomedicine. NO was named the "star molecule" by American Science magazine in 1992, and then the Nobel Prize in Physiology or Medicine in 1998 was awarded to three American pharmacologists for the discovery of "NO as a signal molecule of the cardiovascular system," which aroused great attention in the field of life science toward its biological effects and mechanism of action (2).

$\mathrm{NO}$ is a cellular messenger and effector molecule. It has the characteristics of simple structure, easy diffusion, strong reactivity, lively and unstable properties, and short biological half-life (about 2 s) (3). Further, NO-an inorganic-free radical with dual functions in organisms-is a special biological signal transmission molecule, which is produced and released by vascular endothelial cells

Abbreviation: NO, Nitric oxide; NOS, Nitric oxide synthase; nNOS, Neural NOS; eNOS, Endothelial NOS; iNOS, Inducible NOS; CNOS, Constituent (or structural) synthase; SGC, soluble guanylate cyclase; PKC, protein kinase C; GnRH, gonadotropin-releasing hormone; LH, Luteinizing Hormone; FSH, Follicle-Stimulating Hormone; SNP, Single nucleotide polymorphism. 
and participates in various physiological and pathological processes in the nervous, circulatory, respiratory, digestive, and immune systems (4). In the female reproductive system, NO influences successive reproductive processes, such as follicular development, oocyte maturation, ovulation, corpus luteum degeneration, fertilization, embryo implantation, maintenance of pregnancy, regulation of delivery, and menstrual/estrous cycle regulation. In the male reproductive system, $\mathrm{NO}$ affects progressive reproductive processes, such as spermatogenesis, sperm maturation, and capacitation (5). Recently, the study of NO in animal reproduction has stimulated widespread interest. Through research on the effect of $\mathrm{NO}$ on the reproduction of mice, pigs, cattle, and other animals, the understanding of NO has also been greatly enhanced.

\subsection{Properties and Synthesis of NO}

NO has physiological functions, such as relaxing blood vessels, transmitting nerve signals, and inhibiting platelet adhesion (6). With free radical chemical properties and diverse biological functions, it is an important information and effector molecule in organisms. It significantly affects cell information transmission, cell defense and damage, and mammalian reproductive activity (7). It is a gas signal molecule, which can act not only on the cells producing it, but also on the cells adjacent to it and widely influences various physiological and pathological processes in organisms.

In vivo, $\mathrm{NO}$ is synthesized by three kinds of nitric oxide synthase (nitric oxide synthase, NOS) (8). NOS is the rate-limiting enzyme in the $\mathrm{NO}$ reaction pathway. The reaction of $\mathrm{NO}$ in vivo: $\mathrm{L}-$ arginine $+3 / 2 \mathrm{NADPH}+\mathrm{H}^{+}+2 \mathrm{O}_{2}=$ citrulline + nitric oxide $+3 / 2$ NADP, is catalyzed by NOS (9). Three types of NOS exist: nNOS, eNOS, and iNOS (10). Among them, nNOS and eNOS are calciumdependent, also known as cNOS, with no interspecific specificity, whereas iNOS is non-calcium-dependent with interspecific specificity. eNOS is mainly distributed in vascular endothelial cells, platelets, myocardial intima, brain, and nerve tissues of animals. Normally, it catalyzes the production of basic NO. nNOS is mainly present in the brain, spinal cord, peripheral nerves, and to a small degree, in the bronchi, trachea, and bones (11). In nerve tissues, nNOS only secretes a little NO when neurons need it. iNOS is distributed in many other tissues, except nerve tissue, and is induced by inflammation and immune response only (12). The CNOS gene is expressed at a low level under physiological conditions, but its activity increases rapidly under the action of agonists; the effect time occurs within a few seconds, whereas iNOS is not expressed under physiological conditions; its expression is regulated by cytokines, such as endotoxin, inflammatory cytokines, and nuclear factors, but the amount of NO produced by iNOS expression is significantly higher than that by cNOS expression; it also performs the greatest function in the cytotoxicity, cell growth inhibition, and cell protection processes (13).

\subsection{Physiological and Pathological Effects of NO}

The presence of NO in many physiological and pathological events enhances the in-depth study of NO, it may have positive or negative effects on a specific physiological or pathological event.
Physiological concentrations of NO are involved in information transmission and cytoprotection. Excessive or insufficient levels can cause pathological effects. NO deficiency can be treated by supplementation, while excessive NO has a toxic effect. When the NO content increases to a level of $20 \mu \mathrm{M}$, it can react quickly with the surrounding superoxide anion $\left(\mathrm{O}_{2}{ }^{-}\right)$to form peroxynitrite (ONOO-) (14). $\mathrm{ONOO}^{-}$is a strong oxidant that can effectively oxidize protein sulfhydryl groups, iron-sulfur centers, and zinc finger structures, nitrifying protein tyrosine residues, inactivating many important proteins and enzymes, affecting cell metabolism, inhibiting respiratory chain enzymes, destroying mitochondrial structure, breaking DNA, and initiating lipid peroxidation, resulting in tissue damage (15). When $\mathrm{NO}$ and $\mathrm{O}_{2}{ }^{-}$are relatively excessive, $\mathrm{N}_{2} \mathrm{O}_{3}$ can be formed through a series of reactions and can react with sulfhydryl and amino groups to form nitrosamines, which can inhibit the functions of some proteins, such as the ability to repair DNA damage, resulting in cell death or gene mutation. NO, as a signal molecule or free radical, bidirectionally influences many aspects of an organism's physiology, including apoptosis, protection from degenerative changes of the nervous system, protection from toxicity, and inhibition or promotion of a pathological process.

\subsection{The Mechanism of NO Action}

The biological mode of action of NO involves NO-mediated activation or inhibition of a particular enzyme, or reacting with $\mathrm{O}_{2}{ }^{-}$to $\mathrm{ONOO}^{-}$and cause tissue damage (16). Presently, the most widely accepted mechanism of the NO intracellular pathway is the binding of NO to soluble guanylate cyclase (sGC) and activating sGC to increase cellular cGMP concentration. When the concentration of cGMP increases, the activation of cGMPdependent protein kinase $G$ induces a decrease in intracellular calcium concentration, which mediates vascular smooth muscle relaxation, platelet aggregation inhibition, vascular permeability increase, and other biological effects (17) (Figure 1). Among the many types of GC, only sGC is the target enzyme of NO. NO can recognize $\mathrm{Fe}^{2+}$ and the heme-assisted group in $\mathrm{sGC}$ and change the pathway of sGC, thus activating the enzyme and promoting GTP cyclization to cGMP (18). However, other mechanisms of action of NO, such as affecting protein function, may be Snitrosation-mediated. The heme-containing group reaction between $\mathrm{NO}$ and protein is reversible, whereas most of the effects induced by $\mathrm{NO}$ are irreversible, and can also be mediated by tyrosine nitration, cyclooxygenase and protein kinase $\mathrm{C}(\mathrm{PKC})$ activation, adenylate cyclooxygenase activity inhibition, and the apoptotic pathway. Besides, NO can affect intercellular and intracellular signaling pathways by inhibiting free amino acid, polypeptide, and protein additions, and activating coxidase, PKC, and apoptosis pathways (19).

\section{REGULATION OF NEUROENDOCRINE BY NO}

The nervous system controls NO levels as a regulator of the nitrogen energy system (20). NO exists in the hypothalamus, pituitary gland, 


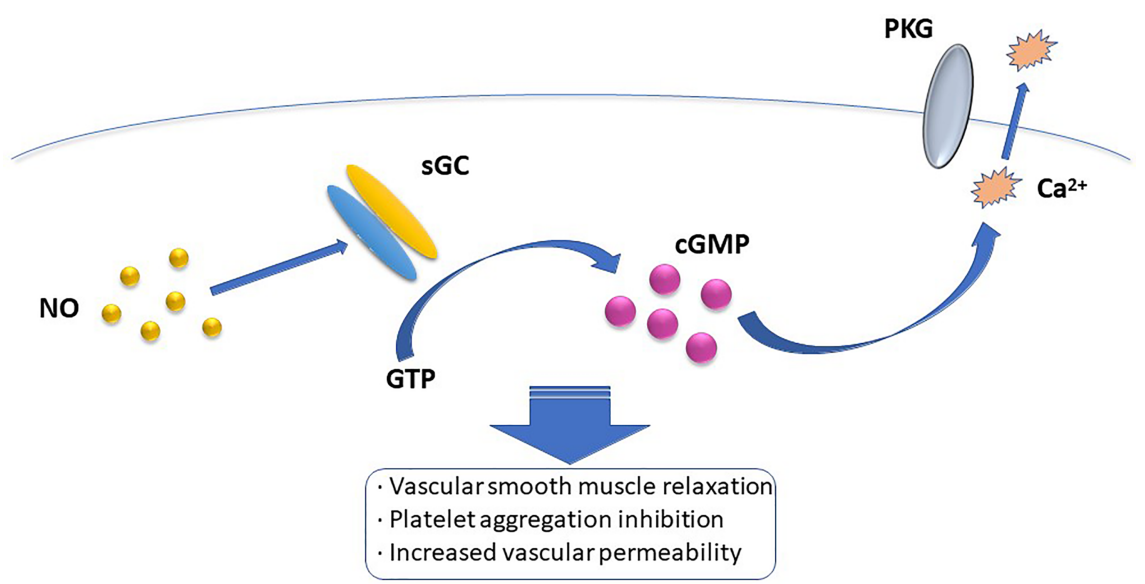

FIGURE 1 | The most widely accepted mehanism of intracellular NO pathway is that NO binds to soluble guanylate cyclase (sGC) and activates sGC to increase intracellular cGMP concentration. When the concentration of cGMP increases, the activation of cGMP dependent protein kinase G induces a decrease in intracellular calcium concentration, which mediates the biological effects of vascular smooth muscle relation, platelet aggregation inhibition, and increased vascular permeability.

and gonadal glands and can act on the hypothalamus to regulate gonadotropin-releasing hormone $(\mathrm{GnRH})$. The position of NOproducing neurons in the hypothalamus is similar to that of $\mathrm{GnRH}$ neurons. NO stimulates hypothalamic neurons to secrete $\mathrm{GnRH}$ (21). NO can also regulate the release of gonadotropins and stimulate the formation of the preovulatory luteinizing hormone (LH) peak (22). The increase in iNOS during follicular development is consistent with the peaking of $\mathrm{LH}$ (23). However, some researchers believe that NO can inhibit hormonal release from pituitary cells. NO can also regulate gonadal hormones, and sex hormones and NO can regulate each other. For example, in the follicular stage, estrogen can upregulate $\mathrm{NO}$ levels, progesterone can downregulate NO secretion, and estradiol $\left(\mathrm{E}_{2}\right)$ can protect blood vessels via $\mathrm{NO}(24)$. $\mathrm{NO}$ also influences signal transduction pathways in releasing adrenocorticosterone. In physiological and pathological processes, NO influences the neuroendocrine and neuroimmune systems and produces various interactions. nNOS affects learning regulation and memory and is involved in neuropsychiatric disorders, including depression. NO produced in stress response has been linked to behaviors similar to depression and anxiety. Besides, NO, produced by $\mathrm{nNOS}$ and iNOS in brain structures, is involved in regulating the HPA axis. Like neurotransmitters, NO can spread rapidly in the mammalian central nervous system membrane, which is one of the reasons why NO is more effective than other transmitters. Studies have found that when exposed to stress, the interleukin levels in the body will increase, and interleukin-related inflammation will cause iNOS expression by stress media, such as toxic fumes or chemicals, thus increasing the NO content. Therefore, iNOS and NO are related to the pathophysiology of stress-induced inflammation (25). Studies on sympathetic nerve-mediated cardiovascular diseases have found that the expression of nNOS in the paraventricular nucleus of the hypothalamus is decreased, whereas the expression of nNOS is increased in mice with spontaneous hypertension and vascular hypertension, which suggests that the expression of nNOS depends on whether the sympathetic nerve is excited (stimulated) or not (26).

\section{THE ROLE OF NO IN THE REPRODUCTION OF FEMALE ANIMALS}

\subsection{NOS Expression in Follicles}

NOS is the only enzyme involved in generating NO. Studying the distribution of NOS is of great significance in clarifying the mechanism of NO. For several mammals, NO affects ovarian steroid and follicular development, atresia, ovulation, oocyte quality, and luteal function. The three NOS subtypes were expressed in the cervix of rats, but only eNOS and iNOS were expressed in the uterus (27). Recent studies have reported the presence of nNOS in pig ovaries (28). iNOS was mainly found in the granulosa cells of healthy immature follicles in rat ovaries, while eNOS was detected in granulosa cells at all stages of follicular formation in cattle (29). NOS is expressed differently in different animals, mainly in immature follicles in mice (30), and mainly in preovulatory and luteinized follicles in pigs. eNOS was expressed in oocytes, vascular endothelial cells, granulosa cells, theca cells, and cumulus cells of porcine large follicles $(7-10 \mathrm{~mm})$, but not in cumulus cells of mediumsized follicles $(3-6 \mathrm{~mm})$ (31). In the early stage of porcine follicular development, NOS is rarely expressed in granulosa and theca cells, and nNOS and iNOS are expressed in granulosa cells with cavity follicles (32). Previous studies have found that $\mathrm{NO} / \mathrm{sGC} / \mathrm{cGMP}$ (a signaling pathway mediated by cyclic nucleotides in NO) has a functional significance in the ovary of perch and can regulate maturing follicular oocytes in bass (33). Additionally, it was found that the expression of eNOS, iNOS, and nNOS, such as in freshwater catfish, was seasonally dependent and cell-specific. All NOS subtypes are expressed only in the reproducible ovaries and not in the stationary ovaries, although very weak nNOS immunoprecipitation was occasionally found in the nuclei of perinuclear oocytes and the cytoplasm and nuclei of inactive ovarian oocytes (34). In human and pig follicles, the 
higher the concentration of nitrite/nitrate (NOx), the larger the follicle and the higher the concentration of $\mathrm{E}_{2}$ (35).

\subsection{NO and the Growth and Development of Preantral Follicles}

Follicular development is regulated by various factors, such as cytokines, growth factors, and locally produced hormonal substances, among which NO may play an important role. Studies have shown that the level of NO changes during follicular growth (36), indicating that NO may influence the process of follicular development. The presence of iNOS and eNOS in theca cells is related to the synthesis of NO and importantly affects the normal development of follicles cultured in vitro (37). Immature follicle development induced by chorionic gonadotropin in equine animals is related to the increased expression of eNOS, while the induction of human chorionic gonadotropin increases both iNOS and eNOS isozymes (38). In a study of preantral follicles, it was found that a $0.1 \mathrm{mM}$ single-nucleotide polymorphism (SNP) did not affect antral follicle formation, but high concentrations inhibited follicular cavity formation. NO has been suggested to play a dual role in regulating follicular development. The effect of $\mathrm{NO}$ on follicular growth and development may be caused by vasodilation, which affects follicular blood flow (39). In the ovaries, the expression and activity of NOS subtypes vary greatly among different animal species and different ovarian processes. The expression of NOS subtypes (nNOS, iNOS, and eNOS) differs at different stages of buffalo follicle development (preantral follicles, antral follicles, and ovulating follicles). iNOS showed stronger immune reactivity in granulosa cells of these three follicle types, indicating that iNOS protein was more common than eNOS and nNOS in buffalo ovaries (40).

$\mathrm{NO}$ is related to the synthesis and secretion of GnRH, FSH, LH, $\mathrm{E}_{2}$, progesterone $\left(\mathrm{P}_{4}\right)$, and prostaglandin in many animals $(41,42)$. Gonadotropins can promote the maturation of oocytes and regulate the secretion of steroid hormones in granulosa cells, thus affecting follicular development. The development of preantral follicles is the process by which follicular cells acquire the ability to respond to gonadotropins. Thyroid hormones importantly affect the reproductive function. T3 is an iodinated tyrosine converted by thyroid hormone, which can promote follicular growth and granulosa cell development induced by FSH in vitro. Studies have found that the synergism of T3 and FSH can significantly increase the expression and translocation of glucose transporters in cells and glucose uptake. These changes were accompanied by upregulated NOS3 expression and increased total amount of NO and activity of NOS3 (43).

\subsection{NO and Oocyte Maturation}

Oocyte maturation requires specific genes to be accurately expressed at a specific time. Concerning the effect of $\mathrm{NO}$ on oocyte maturation, it was found that the number of ovulations was reduced and meiosis was abnormal in mice injected with NOS inhibitor. Compared with that of normal mice, the ovulation rate of eNOS knockout mice was significantly reduced, oocyte meiosis was abnormal, and oocyte mortality was increased (44). It was further confirmed that $\mathrm{NO}$ significantly affects oocyte maturation, which is related to cumulus cells. The maturation of the cumulus-oocyte complex is controlled by the NO/NOS system (45). The results showed that aminoguanidine (AG, a specific iNOS inhibitor) significantly inhibited the recovery of meiosis in porcine oocytes, while L-NAME inhibited the excretion of the first polar body. In early follicular development, eNOS was less expressed in oocytes and granulosa cells, whereas in late follicular development, eNOS was more significantly expressed in oocytes and granulosa cells (46).

A certain concentration of $\mathrm{NO}$ can promote the maturation of oocytes; iNOS-derived NO can regulate the rupture of mouse germinal vesicles and the excretion of the first polar body (47). The lack of NO inhibits meiosis and maturation of oocytes. For example, the NOS inhibitor L-NAME has a significant inhibitory effect on oocyte maturation, and this inhibitory effect can be altered by SNP (45). This may be due to increased cGMP levels and decreased cAMP activation, which promote oocyte maturation. However, excessive NO also inhibits oocyte maturation, which is achieved by inhibiting $E_{2}$ secretion from the pregnant equine granulosa cells of follicles. At present, the specific mechanism of NO/NOS in oocyte maturation is not clear and requires further study.

\subsection{NO and ovulation}

Ovulation-a complex process involving gonadotropins, steroids, some cytokines, prostaglandins, leukotrienes, and histamines-involves various ovarian cells and requires several information transmission pathways and specific gene expression. Currently, a large amount of data show that NO is related to ovulation (48). NO levels increase with follicular development (28), and this increase was associated with $\mathrm{E}_{2}$ concentration. NO is associated with vascular remodeling. Therefore, NO is speculated to be an important mediator of vascular changes and tissue remodeling during ovulation and luteinization. Both non-specific NOS inhibitors, AG and L-NAME, significantly inhibited ovulation in rats in a dose-dependent manner, and this inhibitory effect could be reversed by NO donor SNP (49). NO production is an important physiological feature in normal ovulation cycles. In a study of mouse follicles, it was found that a local level of NO activity was necessary for normal follicular development. NO deficiency reduced the growth and ovulation of mouse follicles. For example, L-NAME treatment in rabbits reduced the production of large follicles, in vitro L-NAME treatment reduced the rate of follicular rupture, and NO gene knockout mice showed altered estrous cycle and reduced ovulation rate (50). Excessive NO also inhibits ovulation, including disruption of tyrosine kinase domain of Ron receptor knockout, increasing NO levels and subsequently decreasing ovarian volume and ovulation rate (51).

NO can regulate ovulation via hormones. NO can increase the release of $\mathrm{LH}$ before ovulation, thus promoting the occurrence of a preovulatory LH peak, while LH acts on theca cells, promoting theca interna cell differentiation and androgen secretion, and stimulating follicle development, maturation, and ovulation (52). In mice, inhibin A produced by FSH-stimulated granulosa cells mediated the formation of the $\mathrm{LH}$ peak before ovulation (22). NO regulates many hormones, including those of 
the entire reproductive endocrine axis, such as $E_{2}$, which exhibits a bidirectional regulatory effect on ovulation. For example, in mice, NO levels were consistently elevated before ovulation, while $\mathrm{E}_{2}$ and $\mathrm{LH}$ were correspondingly upregulated and peaked just before ovulation. Simultaneously, some studies have shown that $\mathrm{NO}$ can inhibit $\mathrm{E}_{2}$ synthesis in granulosa cells when increased to a certain concentration. NO inhibits steroid hormone synthesis, promotes ovulation, and inhibits differentiation via resting granulocyte cells (53). The main physiological mechanism by which $\mathrm{NO}$ inhibits $\mathrm{E}_{2}$ synthesis in granulosa cells is as follows: 1) NO inhibits $\mathrm{E}_{2}$ synthesis in mice by reducing aromatase mRNA and inhibiting aromatase activity, 2) NO inhibits nitrourea formation by binding to the cysteine of aromatase heme, and 3) the endometrium can express high mobility group box 1 (HMGB1) in a process which is regulated by $\mathrm{E}_{2}$, progesterone, and $\mathrm{NO} . \mathrm{E}_{2}$ increases the expression of HMGB1, and progesterone decreases the expression of HMGB1. Both $\mathrm{E}_{2}$ and progesterone can regulate the expression of iNOS and the production of $\mathrm{NO}$ in the endometrium (54). After the eNOS gene was knocked out, the secretion of progesterone in the ovaries of mice was significantly reduced.

NO deficiency inhibits GnRH release and affects release of FSH and LH. For example, Barnes found that chronic NO deficiency decreased the release of $\mathrm{GnRH}$ in the hypothalamus of female rats, accompanied by a decrease in $\mathrm{LH}$ and $\mathrm{FSH}$ secretion. Similarly, excessive NO can also inhibit the secretion of pituitary and hypothalamic hormones. Mouse graft experiments in vitro have shown that excessive NO can inhibit the release of $\mathrm{GnRH}$ and $\mathrm{LH}(55,56)$.

NO can also regulate ovulation by affecting other reproductive hormones. In mice, NO can inhibit the release of inhibin-a hormone associated with oocyte maturation and stimulated by $\mathrm{FSH}$ - to mediate the formation of $\mathrm{LH}$ peak before ovulation and enhance follicular exception by producing PGE and PGF2a via the trioxygenase pathway. The process of NO-facilitated hormonal ovulation is more complex and involves not only the hormone and NO regulating each other, but also many other substances.

NO can also affect vascular permeability to regulate follicular pressure and rupture. For example, NOS inhibitors can inhibit the expansion of mouse follicular vessels, reduce the flow of follicular fluid into the follicular cavity (57), reduce follicular pressure, and affect ovulation.

\subsection{NO and Follicular Atresia}

Studies have shown that cGMP is related to oocyte maturation, and intracellular cGMP can be regulated by NO. Three NO synthases and four soluble Guarnidase (sGC) were found to be expressed in the ovary. Interestingly, activation or inhibition of the $\mathrm{NO} / \mathrm{sGC} / \mathrm{cGMP}$ pathway in fully grown follicles may lead to oocyte maturation. During oocyte maturation, cGMP level in follicular cell layer increased, oocyte level decreased, NO level in follicular cells increased and oocyte remained constant (58).

The microenvironment of ovarian follicles is also critical for normal oocyte development, follicular generation, and timely ovulation. High concentrations of NO in the follicular fluid can be harmful, affecting the maturation of oocytes and embryos, and greatly reducing the success rate of in vitro fertilization $(59,60)$. However, low $\mathrm{NO} 3 / \mathrm{NO} 2$ level in follicular fluid is beneficial to fertilization and stable embryo implantation (61). Studies have shown that NO in follicular fluid is a marker of follicular hypoxia and suboptimal embryo development (62). In addition, having endometritis reduces the level of nitric oxide in the follicular fluid, impairing the growth and composition of the largest follicles (63).

The follicles that finally ovulate in the ovary undergo follicular genesis, follicular recruitment, and follicular selection. During the selection, most follicles undergo physiologic atresia. Finally, only a few follicles develop into the dominant follicle and mature at ovulation. Normal follicular function may be reflected in cell proliferation and apoptosis, the expression of regulatory factors, and the production of hormones that essentially affect reproduction and the production of healthy offspring (64). Whether developing follicles form dominant follicles or closed follicles is dependent on many factors. NO can influence follicular atresia. Many studies have shown that follicular atresia is the result of follicular cell apoptosis; that is, apoptosis is the mechanism of follicular atresia. Follicular atresia is regulated by complex signals of cell death and survival (65).

NO mainly affects follicular atresia by affecting apoptosis in the granulosa cells. Studies have found that iNOS can inhibit the apoptosis of rat granulosa cells via autocrine and paracrine pathways and prevent early follicular atresia. The results showed that the spontaneous apoptosis of cultured granulosa cells from rats could be directly inhibited by SNP treatment without the addition of donor S-nitrose-N-acetylpenicillamine (29). Granulosa cell degeneration is hypothesized to be the cause of follicular degeneration. Granulosa cells often degenerate first. The inability of granulosa cells to transport nutrients and signaling factors to oocytes leads to microvillus degeneration of oocytes and oocyte atresia. NO can also inhibit apoptosis of preovulation follicles in mice by stimulating heat shock protein 70 (HSP70) and inhibiting Bax expression (66). Studies have shown that the Fas/FasL system is a key factor mediating apoptosis during ovarian follicular atresia. NO can regulate the expression of apoptosis-related genes in granulosa cells. In the detection of related proteins, NO was found to inhibit the apoptosis of human granulosa cells by reducing the expression of genes that promote granulosa cell apoptosis, such as Fas, P53, and Bax, and promoting the expression of genes that inhibit apoptosis, such as Bcl-2 and HSP70. NO can inhibit the apoptosis of granulosa cells by inhibiting the cysteine aspartic enzyme in the Fas/FasL-mediated apoptosis pathway (67). NO has a dual effect of promoting or inhibiting apoptosis. It has been found that high levels of NO can inhibit the apoptosis of bovine granulosa cells (68), while NO can promote the apoptosis of welldifferentiated granulosa cells (such as macrofollicular granulosa cells). NO not only regulates cell apoptosis during follicular development but also the survival and apoptosis of follicular granulosa cells after ovulation, thus modulating the estrus cycle.

The role of NO in controlling follicular angiogenesis depends on the establishment and continuous remodeling of complex 
vascular systems. This enables the follicle to receive the nutrients, oxygen, and hormonal support it needs and promotes the release of steroids (69).

NO can also regulate follicular atresia through its interaction with hormones. NO chiefly regulates the secretion of estrogen and progesterone; for example, progesterone can promote follicular atresia by inhibiting the frequency of LH fluctuations; however, the mechanism remains unclear. NO may be involved in the regulation of apoptosis in the whole follicular development cycle. However, how NO regulates follicular atresia through apoptosis remains controversial, as it has been documented to exhibit a dual effect, mainly depending on the concentration.

\subsection{NO and Fertilization}

Studies have shown that NO is produced by cells in the female reproductive tract. The enzyme responsible for NO synthesis can be regulated by sex hormones, and NO levels change during the estrus cycle, thus regulating fertilization. NO can affect oocyte activation during fertilization by regulating $\mathrm{Ca}^{2+}$, and the $\mathrm{NO}$ in fertilization is derived from the activation of eNOS in spermatozoa and oocytes. The NO-mediated regulation of oocyte $\mathrm{Ca}^{2+}$ influences the chain regulation of several substances. The increased expression of NO first activates guanylate cyclase, and the increased cGMP activates cyclic adenosine diphosphate ribose to promote the release of $\mathrm{Ca}^{2+}$ under conditions of inositol triphosphate activation. During fertilization, NO may be obtained from the spermatozoa, which has abundant NOS. NO can be produced during the sperm replacement reaction at 30-45 s after fertilization; as the expression of $\mathrm{NO}$ increases in spermatozoa, $\mathrm{Ca}^{2+}$ also increases. Because nNOS is sensitive to $\mathrm{Ca}^{2+}$, the continuous increase in $\mathrm{Ca}^{2+}$ promotes the production of many NO molecules.

NO regulates sperm capacitation, acrosomal reaction, sperm motility, and may also have an antiapoptotic effect. Low concentrations of NO may physiologically affect fertilization by enhancing the ability to bind to the zona pellucida (ZP), rather than by inducing acrosomal reaction or promoting oocyte penetration. The addition of a NOS inhibitor to the capacitation medium of the human spermatozoa can reduce the fertilization rate. When spermatozoa were treated with LNAME, they could bind the ZP but not the cytoplasmic membrane (70). The activation of NOS may require binding the cytoplasmic membrane. A low concentration of L-NAME may increase the fertilization rate of cryopreserved mouse oocytes, whereas a high concentration of L-NAME (10-3 M) or SNP (10-6 M) inhibits the normal functions of spermatozoa and oocytes, indicating that there is normal physiological demand within a certain range, which leads to toxicity if exceeded. For example, polyspermia may occur in some cases of infertility, while previous studies have focused on the role of $\mathrm{NO}$ in reproductive physiology; the optimal regulation of NOS enzymes is key to this process.

\subsection{NO and Embryonic Development}

Embryos develop rapidly and require messengers to transmit information quickly. As a signaling molecule, NO transmits information via diffusion, participates in the regulation of the division and differentiation of mammalian embryos, and importantly affects cell proliferation and differentiation. NO is required in instances where the rat embryo develops from two to four cells (71). Studies have shown that embryonic development is delayed or stemmed by inhibition mediators from the two-cell to the blastocyst stage (72). When embryos were treated with exogenous NO, it was found that $0.1 \mathrm{M}$ SNP inhibited the transformation of mouse mulberry embryos into blastocysts but promoted the growth of trophoblasts, indicating that different concentrations of SNP had different effects on embryos at different developmental stages. An appropriate increase in NO significantly regulates the embryonic development, and the demand for NO may be high during the development of the embryo; a too-high or too-low NO level may interfere with normal development.

Moreover, studies have shown that the level of NO significantly affects the development of embryos during their early development (73). A high level of NO changes the position of the heart from right to left, causing situs invertus (74). Embryos may be affected by various factors during development, and damage restoration is a complex process that requires not only proteins but also RNAs. Studies have shown that NO essentially influences embryonic damage, inflammation, blood vessel formation, and is important for the expression of treatment-related genes. However, such damage mainly occurs in the early stages of embryonic development, and $\mathrm{NO}$-mediated tissue remodeling can occur under the skin, but the process requires a relatively long time (75).

\subsection{Effects of NO on Reproductive Cycle and Fertility Of Female Animals}

NOS requires significantly longer time to be knocked-out, but iNOS does not, suggesting that eNOS-derived NO rather than iNOS-derived NO affects the reproductive cycle and fertility of female animals; mice that drank L-NAME water and those lacking NO continually exhibited a state of persistent estrus owing to the increase in $\mathrm{E}_{2}$ production (76). By measuring NOS at different stages of estrus and the menstrual cycle, different subtypes of NOS were found in the fallopian tubes of mice and humans, and increased expression of iNOS was found in the fallopian tubes of women with ectopic pregnancy, such as that involving heart inversion. The increased iNOS activity may affect ovulation, ciliary pulsing, contraction, and embryo transport, thereby increasing the risk of ectopic pregnancy. These results suggest that iNOS essentially affects the reproductive cycle and infection-mediated ectopic pregnancy. As a fungicide, $\mathrm{NO}$ is lethal to intracellular pathogens and causes diseases such as trachoma; therefore, it is considered a part of the innate immune response and can protectively influence embryo development (77).

\subsection{Regulation of NO on Pregnancy Physiology}

\subsubsection{The Role of NO in Embryo Implantation}

Embryo implantation is a complex process that requires endometrial interactions. Previous studies have shown that NOS essentially affects trophoblast cell recognition and 
remodeling, and only appropriate concentrations can lead to successful embryo implantation (78).

NO regulates embryo implantation from two aspects of embryo development and helps create the uterine environment, and it can regulate the $\mathrm{cAMP} / \mathrm{cGMP}$ ratio to affect embryo division and differentiation. The cAMP/cGMP ratio significantly affects embryo growth, development, and differentiation. NO promotes the production of cGMP, which is the main regulator of the $\mathrm{cAMP} / \mathrm{cGMP}$ ratio; thus, normal embryonic development requires NO regulation (79).

NOS can be detected before and during the implantation of early mammalian embryos. Studies have shown that mouse embryos produce NO during the first four days of pregnancy. When embryos after the two-cell stage were cultured in a medium containing LNAME, the proportion of their development to the corresponding later stage was significantly lower than that in the control group, and this block could be relieved by $\mathrm{E}_{2}$, because $\mathrm{E}_{2}$ can stimulate $\mathrm{NO}$ production (72). Besides, the normal implantation of embryos requires a suitable uterine environment, and NOS activity in the uterus is significantly increased before implantation, indicating that $\mathrm{NO}$ is necessary for the formation of the uterine microenvironment. Hindering NO production will trigger abnormal implantation (8082). In the process of embryo implantation, the endometrium undergoes complex changes. Because NO can relax the muscle layer and vascular smooth muscle, inhibit platelet aggregation, and play a role in inflammation, it is a strong candidate molecule for mediating the roles of various steroid hormones and cytokines in the endometrium and decidua (83).

\subsubsection{The Role of NO in Pregnancy Maintenance}

An NO system is known to exist in the uterus, mainly to relax uterine muscle cells, maintain relative rest during pregnancy, and conserve uterine-placental blood perfusion. The increase in NO production during pregnancy inhibits the spontaneous contraction of the uterine muscle bundle, causes vasodilation of the maternal system, reduces the vascular response, and affects the adaptive regulation of maternal cardiovascular system function during pregnancy. During pregnancy, the concentration of NO in the myometrium and placenta increases, which contributes to uterine calm and control of uterus-fetal-placental blood flow (4).

Besides, NO significantly influences placental function and fetal development. NO is a powerful local vascular inhibitor that essentially affects hemodynamics, helping to maintain low vascular resistance in the placental circulation. Successful pregnancy requires maintenance of sufficient placental blood flow, and the placenta lacks autonomic innervation. NO is a strong vascular relaxation factor that strengthens placental blood flow and the exchange of oxygen and nutrients by dilating the umbilical artery vessels. Insufficient production of NO in the fetus and placenta triggers fetal growth retardation. Many studies have shown that the expression of NOS (eNOS) in endothelial cells differs between normal and abnormal pregnancies, and the endocannabinoid system can regulate NO formation or release; however, long-term exposure to four hydrogen marijuana may affect the transfer of maternal and child trace elements, if marijuana use during pregnancy affects the placenta, leading to adverse pregnancy, such as preterm birth and fetal growth restriction. Under pathological conditions, the fetus may be exposed to unhealthy endocannabinoid levels, which may interfere with fetal development and lead to neurophysiological abnormalities.

\subsubsection{The Role of NO in the Initiation of Delivery}

It was found that the changes in $\mathrm{P}_{4}$ before and after delivery had an important influence on the initiation of delivery. $\mathrm{P}_{4}$ can inhibit uterine muscle contraction and stabilize the uterus during pregnancy and, once released, is an important inducer of the initiation of delivery. Uterine NO synthesis and NOS expression are $\mathrm{P}_{4}$-dependent. The initiation of delivery was related to a decrease in NOS activity in the uterus. iNOS levels began to decrease in the third trimester of pregnancy, and uterine NO decreased to the lowest level at the onset of delivery. Further, NO inhibition was relieved, uterine muscle excitability increased, and delivery was initiated. Besides its effect on the uterus, NO also affects the pelvis during delivery. During delivery, the expression of NOS in the pelvis increases significantly, and the production of NO increases, which promotes the opening of the pelvis (84). Relevant studies have revealed that the coordination between endothelium-derived hyperpolarizing factor and NO may also affect gender. When endothelial cells are lacking NO, the endothelium-derived hyperpolarizing factormediated response compensates for the absence of $\mathrm{NO}$, thus achieving gender control. Therefore, it can be speculated that endothelium-derived factors are more important in the female reproductive system than in the male reproductive system (85).

\section{THE ROLE OF NO IN MALE REPRODUCTION}

\subsection{NO and Sperm}

NO seems to play a major role in the regulation of sperm motility, hyperactivation, capacitation, and fertilization (86). Sperm capacitation-a very complex physiological process in which sperm undergoes a series of physiological and morphological changes, and finally obtains the ability to fertilize-is the premise of fertilization, which is affected by many factors, including NO.

Regarding sperm capacitation, NOS has been reported to be expressed in the acrosome and tail of human and mouse spermatozoa. Some researchers hypothesized that low concentrations of NO can improve sperm capacitation. The effect of NO on sperm motility is related to its concentration. Studies have shown that low NO concentrations can promote sperm motility (85), whereas high NO concentrations can inhibit sperm motility (87). The regulatory effect of NO on sperm was not only related to the $\mathrm{NO}$ concentration but also to the exposure time. Other studies have shown that NO has no effect on sperm motility or acrosomal response rates. Previous studies have shown that acrylamide induces the activation and release of bovine sperm from oviduct epithelial cells and that acrylamide acts through NO. Arachidonic acid ethanolamide is an endocannabinoid receptor. Activation of the cannabinoid receptor increases $\mathrm{NO}$ levels and stimulates sperm capacitation or release in the fallopian tube bank (88). 
In terms of motility, stimulation of NO synthesis triggered an immediate decrease in sperm motility, but only at the beginning of the incubation period. After this period, the motility was restored. When sperms were cultured without NO, it was observed that all or part of the motility characteristics of all sperms were reduced, resulting in sperm fixation. Sperm motility is closely related to ATP, and the reduced respiration of sperm also affects sperm motility. The significant inhibition of sperm motility is unlikely to be due to the inhibition of ATP activity, thus reducing the intracellular ATP concentration. Besides, studies have shown that $\mathrm{H}_{2} \mathrm{O}_{2}$ may be involved in this effect.

For diseases, the increased activity of NOS and the increased tyrosine nitrification may be related to the pathogenesis of idiopathic asthenospermia, and the regulation of NO regarding sperm depends not only on the concentration of NO, but also on the time of exposure, which is beneficial to sperm motility. A 1997 study showed that the addition of synthetic inhibitors of NO could effectively reduce NO toxicity to sperms. Moreover, studies have shown that leptin has a certain effect on sperm motility: leptin can influence the survival of pig sperm; leptin in the hypothalamus-pituitary level affects reproductive function and is also involved in the regulation of some peripheral functions; and leptin-treated male gametes can increase the $\mathrm{NO}$ content, triggering the acrosome reaction (89). NO is also associated with certain diseases. For example, in patients with varicocele, the iNOS subtype induces high NO production in varicocele, which can cause decreased sperm motility and even infertility (90).

\subsection{Regulation of Male Reproductive Tissues by NO}

NOS is widely found in Leydig cells, Sertoli cells, spermatocytes, neuronal plexus in the adventitia of arterioles, immature sperm head, vascular endothelial cells, and smooth muscle cells, indicating that NO/NOS can maintain the tension of testicular arterioles, regulate testosterone secretion, and affect sperm development. Moreover, the in vitro culture of interstitial cells or seminiferous tubules showed that NOS was also expressed in interstitial cells and blood vessels, indicating that the testis itself can produce NO (91). Besides, the concentration of NO can determine the sperm level. The NO-CGMP pathway is activated in testicular cells, which may participate in regulating testicular functions, such as spermatogenesis and steroid production.

Pankaj and Chandra found that injection of 5hydroxytryptamine and L-dopamine at $8 \mathrm{~h}$ intervals inhibited the activity of reproductive tissues and significantly decreased the concentration of nitrate-nitrite and NO in reproductive tissues, whereas the opposite results were observed at $12 \mathrm{~h}$ intervals (92). However, the concentration of nitric acid-nitrite in the reproductive tissues increased after reinjection of SNP at $8 \mathrm{~h}$ intervals; the result was the opposite after injection of L-NAME at $12 \mathrm{~h}$ intervals, indicating that the lack of changes in activity in vivo could affect the function of reproductive tissues. Experimental studies found that NO content, NOS activity, and pathological scores of the contralateral testis in the unilateral testicular torsion group were all increased to different degrees, and NO content was positively correlated with pathological score, indicating that the higher the NO concentration, the greater the tissue injury. The injury may result from the formation of more toxic ONOO-, by the combination of NO with oxygen-free radicals on the torsional side, which may damage the contralateral testicular tissue. Alternatively, it may act on the contralateral testicular tissue by accumulating proinflammatory transmitters of $\mathrm{NO}$, excessively dilating blood vessels, and inducing apoptosis (93). Simultaneously, the above-mentioned injury can induce further NOS activation to synthesize NO and cause greater damage, indicating that the effect of $\mathrm{NO}$ on reproductive tissues is dose-dependent.

NO can inhibit testosterone secretion. Therefore, NO may regulate the endocrine function of testosterone through a paracrine mechanism. The expression of nNOS is influenced by testosterone levels in males. In addition, the twoconcentration hypothesis of NO states that low concentrations of NO promote cancer, while high concentrations prevent cancer. Although prostate cancer is a hormone-driven malignancy, research has shifted from epithelial cells that respond to androgens to focus on NO therapy, tumor microenvironment, and inflammation. NO has been reported to inhibit androgen receptor activity. This may prevent prostate growth, but low levels of NO can in turn select for anticircumcision prostate cells, producing an aggressive cancer phenotype. At high levels, nitro stress caused by $\mathrm{NO}$ overproduction can prevent prostate tumors (94)

Importantly, NO plays an important role in the biology of the penis, especially for penile erection. Studies have found that NO causes muscle smooth muscle relaxation, which is the basis of an erection. In this process, NO synthase subtypes have different roles. nNOS initiates erectile response, eNOS promotes maximum erectile response, and iNOS inhibition may lead to penile oxidative stress, suggesting that iNOS may actually promote the protective mechanism of fibrosis and abnormal wound healing. The nitric oxide signaling pathway regulating penile erection is shown in Figure 2 (95).

\section{ROLE OF NO IN OTHER THERAPEUTIC AREAS}

NO, originally considered an environmental pollutant, has gained momentum since its discovery as an endothelial growth factor in 1987. The presence of NO in many physiological and pathological events has enhanced the further study of NO. In clinical studies, NO can be used to treat a variety of diseases: it can be used to treat cardiovascular diseases, such as coronary heart disease, acute myocardial infarction, atherosclerosis, essential hypertension, etc. (96), and can regulate vasodilation, blood pressure and blood flow in the circulatory system (97). As neurotransmitters in the nervous system, modulating the release of various neurotransmitters and mediating excitatory amino acids, synaptic transmission, and neurotoxicity (98), NOS inhibitors are used to treat stroke and reduce NO production to control epileptic seizures. It also affects the 


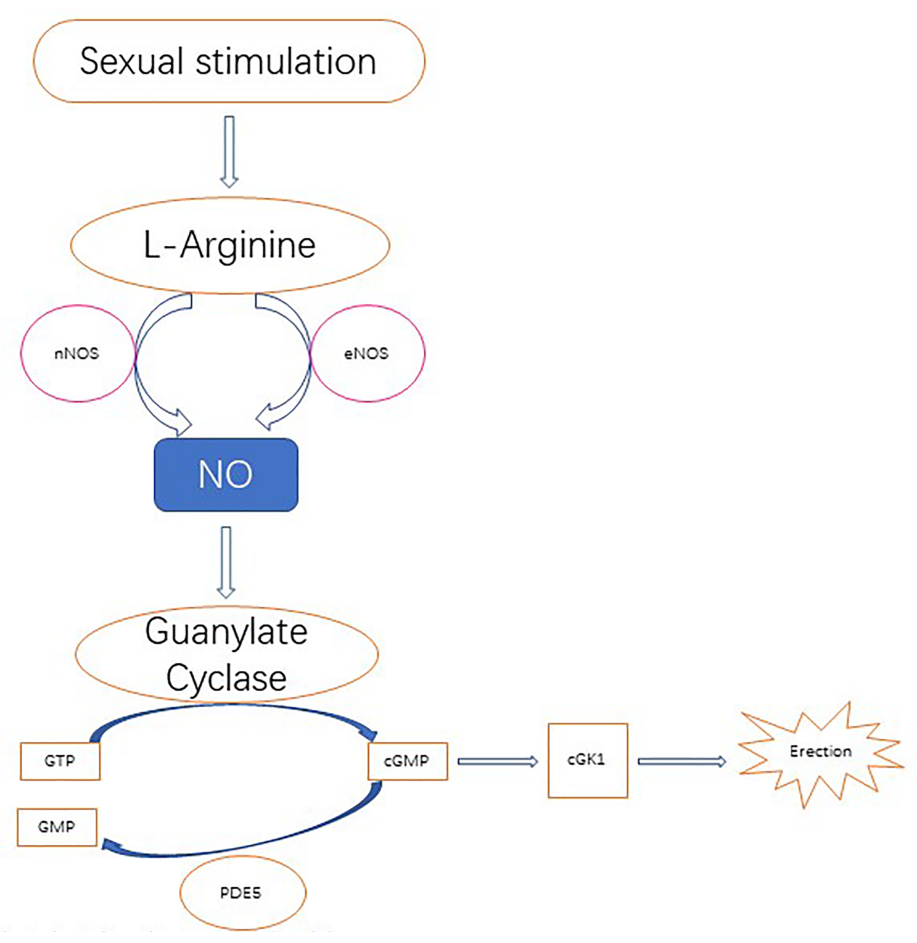

FIGURE 2 | Nitric oxide is derived from its precursor I-arginine and is primarily localized to the nerves and endothelium through the catalysis of neuronal NOS (nNOS) and endothelial NOS (eNOS) following upstream stimulation, respectively. Nitric oxide diffuses to local smooth muscle cells, where it activates guanosine cyclase and then converts 5'guanosine triphosphate (GTP) to $3^{\prime}, 5^{\prime}$-cycloguanosine monophosphate (cGMP). In turn, cGMP activates cGMP specific protein kinase I (cGK I), which produces erections via downstream effectors. CGMP degrades in the catalytic action of phosphodiesterase type 5 (PDE 5 ) to produce inactivated nucleotide GMP. PDE 5 is a molecular target of PDE 5 inhibitor therapy, which enhances nitric oxide signaling.

respiratory system by smooth muscle contraction and pulmonary vasoconstriction (99). Respiratory NO inhalation therapy has been used to treat persistent pulmonary hypertension, primary pulmonary hypertension in neonates, chronic obstructive pulmonary disease, adult respiratory distress syndrome and congenital heart disease with pulmonary hypertension (100). In the respiratory system, NO can be used not only as a diagnostic aid, but also as a management tool to assess severity, monitor treatment response, control asthma symptoms, and identify allergic airway inflammation (101). Because it is non-invasive and readily available, its utility in diagnosing and managing various respiratory diseases has been studied. Most studies have focused on asthma, and many support the use of NO to help diagnose asthma, predict steroid responses, and prevent worsening by directing drug dosing and assessing compliance (102). In the immune system, NO as an immunomodulatory molecule affects the cytotoxicity of macrophages (103), and the selective NOS antagonist dexamethasone is used to specifically inhibit iNOS in the treatment of endotoxin shock (104). A series of in vitro and in vivo detection methods for $\mathrm{NO}$ were developed. These quantitative methods will contribute to a comprehensive understanding of its biological functions and effects (105).

Therefore, a wide range of NO donors has emerged as a potential treatment for cardiovascular and respiratory diseases and cancer, promoting wound healing, and improving immune response to infection. However, short half-life, chemical reactivity, rapid systemic clearance, and cytotoxicity hinder the clinical development of most low molecular weight NO donors. Therefore, in order to control NO release, efforts are being made to design novel NO-releasing biomaterials for tumor targeting (106).

$\mathrm{NO}$ is an antibacterial and anti-inflammatory molecule that plays a key role in pulmonary vascular function under viral infection and other lung conditions. For example, studies have demonstrated the rationale for the use of exogenous NO to control the pathogenesis of COVID-19 and highlighted its potential to help improve clinical outcomes and relieve the rapidly rising pressures on healthcare capacity (107). NO is well known as a vascular adsorbent, an important coagulation mediator, an antimicrobial agent, and an inhibitor of SARS-COV replication. Exhaled NO is strongly associated with the type 2 inflammatory response found in asthma, and the use of inhaled NO has been an effective treatment during this pandemic, as ventilator-perfusion rates in COVID-19 patients have subsequently improved and mechanical ventilation is not required (108).

Because NO is an antibacterial and anti-inflammatory molecule, it represents a potential therapeutic agent for wounds because of its ability to regulate inflammation and eradicate bacterial infections. NO can be utilized for wound healing, with special attention to chronic wounds associated with diabetes (109). NO also plays an important role in the treatment of glaucoma, a disease that causes irreversible blindness. NO regulates blood flow in the eye and protects 
the optic nerve. Therefore, NO has broad research prospects for antiglaucoma drugs (110). Studies have shown that NO is related to the aging of various plant organs; however, whether it can be applied to human medical cosmetology remains to be studied, which will be a potential development (111). On the cardiac side, inhalation of NO can be used to treat a variety of cardiopulmonary disorders, including pulmonary hypertension in children and adults and cardiac arrest syndrome (112). However, the popularity may not be very widespread for cost reasons, and efforts are currently being made to develop cost-effective and simple devices for inhalation therapy (113). In the digestive system, NO plays an important role in gastrointestinal mucosal defense and the pathogenesis of a variety of gastrointestinal diseases, such as irritable bowel syndrome and inflammatory bowel disease. The potent cellular protective effects of $\mathrm{NO}$ have been demonstrated in a range of animal models. However, in some disease states, inhibition of NO synthesis may be beneficial. Several attempts have been made to develop drugs to treat gastrointestinal ulcers and/or inflammatory diseases, with varying degrees of success (114). At the same time, NO also plays a role in insulin secretion and glucose metabolism, which can improve diabetes (115).

Research has shown that NO also plays a big role in cancer treatment. Low levels of NO can inhibit apoptosis and promote cancer, while high levels of $\mathrm{NO}$ can promote apoptosis of cancer cells. NO is an important product of arginine in cancer cells, so arginine consumption may contribute to tumor suppression by reducing the level of NO in cells. NO related anticancer strategies include those to increase NO levels and those to decrease NO levels (Figure 3) (116).

\section{CONCLUSION}

In conclusion, $\mathrm{NO}$ affects all stages of the mammalian reproductive process and is expressed differently at different stages. $\mathrm{NO}$ is involved in various physiological and pathological processes of nervous, circulatory, respiratory, digestive and immune systems and is associated with a variety of diseases. So, normal secretion of $\mathrm{NO}$ has some significance for many diseases. If this disorder occurs, it can lead to related diseases, such as diabetes, cardiovascular disease, pulmonary hypertension, rheumatoid arthritis, gastritis or stomach ulcers, and even cancer or tumors.

In the female reproductive system, $\mathrm{NO}$ affects reproductive processes such as follicular development, oocyte maturation, ovulation, luteinization, fertilization, embryo development, pregnancy maintenance, childbirth, and regulation of the menstrual cycle. At the same time, if NO is not secreted during pregnancy, it can lead to fetal abnormalities. In the male reproductive system, NO affects a series of reproductive processes such as spermatogenesis, sperm maturation, and capacitation. Serious deficiency will cause a decline sperm vitality or even infertility. All these indicate the importance of

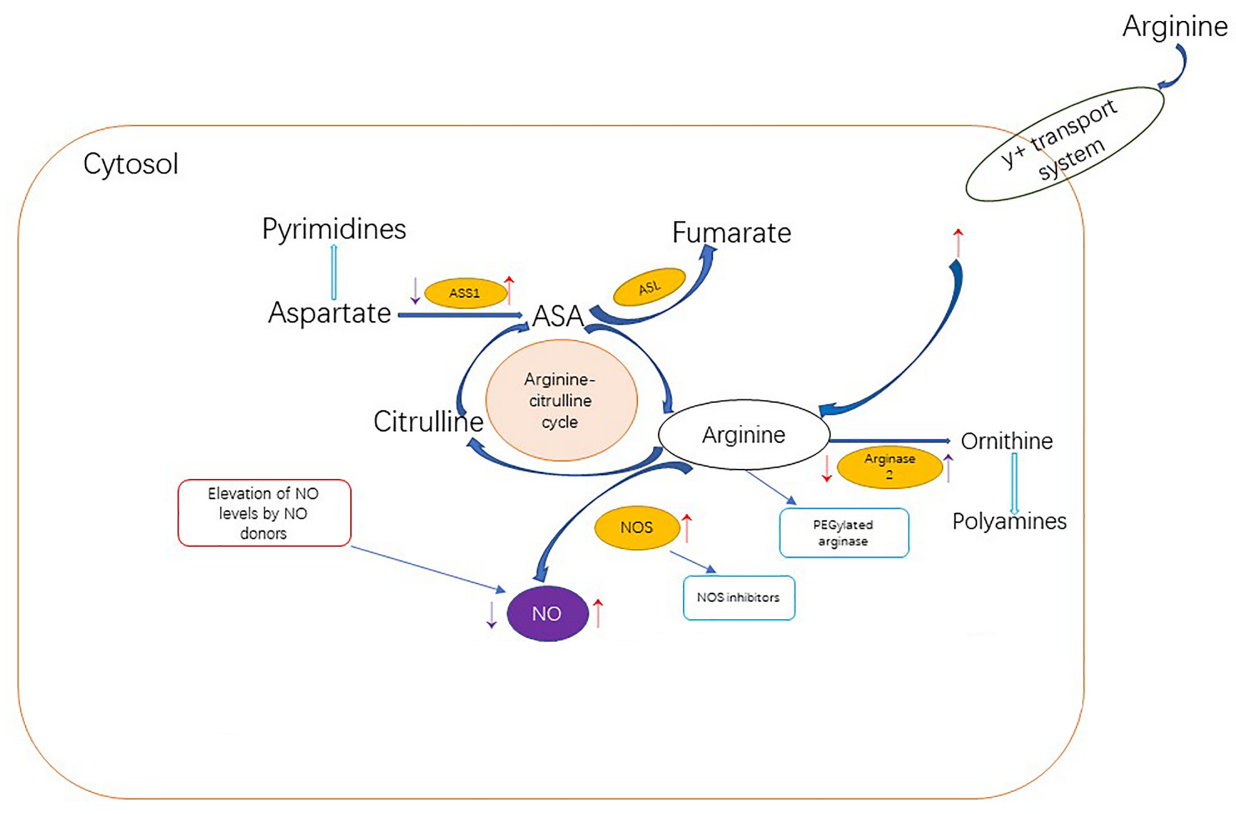

FIGURE 3 | Dietary arginine can enter cells through the $Y+$ transport system or be synthesized endogenous through the arginine-citrulline cycle. The red arrows in the figure indicate up-regulation or down-regulation of cancer-related NO metabolism proteins, resulting in a net increase in NO production. Tumor cells promote NO production through the following pathways: upregulating NOS level; Increased arginine transport;ASS1 and ASL levels were increased to improve the availability of arginine for NO synthesis. Or reduce arginine metabolism by inhibiting arginase The purple arows indicate up-regulation or down-regulation of cancer-related PROTEINS associated with NO metabolism, resulting in a net reduction in NO production. In addition to limiting NO levels, inhibition of ASS1 and upregulation of ARG2 may also support cancer metabolically by increasing pyrimidine and polyamine production. Anti-cancer NO related strategies to increase NO level are represented in the red box, while stategies to decrease NO level are represented in the blue box. 
NO in living organisms. However, the mechanisms by which NO mediates cellular and body changes during pregnancy remain unclear. Changes in these mechanisms can lead to preeclampsia, intrauterine growth restriction, rupture of membranes, and premature delivery. Therefore, the mechanisms of NO need to be further elucidated, and it is of great clinical significance to use NO to prevent these changes and treat fertility diseases.

\section{AUTHOR CONTRIBUTIONS}

$\mathrm{CL}$ and $\mathrm{XZ}$ designed the article. YL wrote the manuscript. YZ and $\mathrm{WB}$ contributed to manuscript writing. $\mathrm{XW}$ revised the

\section{REFERENCES}

1. Palmer RMJ, Ferrige AG, Moncada S. Nitric Oxide Release Accounts for the Biological Activity of Endothelium-Derived Relaxing Factor. Nature (1987) 327:524-6. doi: 10.1038/327524a0

2. Rivero A. Nitric Oxide: An Antiparasitic Molecule of Invertebrates. Trends Parasitol (2006) 22:219-25. doi: 10.1016/j.pt.2006.02.014

3. Dixit VD, Parvizi N. Nitric Oxide and the Control of Reproduction. Anim Reprod Sci (2001) 65:1-16. doi: 10.1016/S0378-4320(00)00224-4

4. Zullino S, Buzzella F, Simoncini T. Nitric Oxide and the Biology of Pregnancy. Vasc Pharmacol (2018) 110:71-4. doi: 10.1016/j.vph.2018.07.004

5. Herrero M, Lamirande E, Gagnon C. Nitric Oxide Is a Signaling Molecule in Spermatozoa. Curr Pharm Design (2003) 9:419-25. doi: 10.2174/ 1381612033391720

6. Dweik RA. Nitric Oxide, Hypoxia, and Superoxide: The Good, the Bad, and the Ugly! Group.bmj.com (2005).

7. Kowalczyk E, Kopff A, Kopff M, Błaszczyk J, Fijałkowski P, Kowalski J. Nitric Oxide Metabolism. Wiadomosci Lekarskie (Warsaw Poland: 1960) (2006) 59:889-93.

8. Förstermann U, Sessa WC. Nitric Oxide Synthases: Regulation and Function. Eur Heart J (2012) 33:829-37. doi: 10.1093/eurheartj/ehr304

9. Gawrys J, Gajecki D, Szahidewicz-Krupska E, Doroszko A. Intraplatelet LArginine-Nitric Oxide Metabolic Pathway: From Discovery to Clinical Implications in Prevention and Treatment of Cardiovascular Disorders. Oxid Med Cell Longevity (2020) 2020:1015908. doi: 10.1155/2020/1015908

10. Ricciardolo FLM, Sterk PJ, Gaston B, Folkerts G. Nitric Oxide in Health and Disease of the Respiratory System. Physiol Rev (2004) 84:731-65. doi: 10.1152/physrev.00034.2003

11. Dweik RA, Erzurum SC. Regulation of Nitric Oxide Synthases and GasPhase Nitric Oxide by Oxygen. In: Disease Markers in Exhaled Breath. CRC Press (2002). p. 266-77.

12. Kobzik L, Bredt DS, Lowenstein CJ, Drazen J, Gaston B, Sugarbaker D, et al. Nitric Oxide Synthase in Human and Rat Lung: Immunocytochemical and Histochemical Localization. Am J Respir Cell Mol Biol (1993) 9:371. doi: 10.1165/ajrcmb/9.4.371

13. Dweik RA, Erzurum SC. Effects of Nitric Oxide and Cyclic GMP on Smooth Muscle Proliferation. Lung Biol Health Dis (1999) 131:333-49. doi: 10.1210/ endo.140.3.6546

14. Forstermann U, Munzel T. Endothelial Nitric Oxide Synthase in Vascular Disease: From Marvel to Menace. Circulation (2006) 113:1708-14. doi: 10.1161/CIRCULATIONAHA.105.602532

15. Dawson TM, Dawson VL. Nitric Oxide Signaling in Neurodegeneration and Cell Death. Adv Pharmacol (2018) 82:57-83. doi: 10.1016/bs.apha. 2017.09.003

16. Prast H, Philippu A. Nitric Oxide as Modulator of Neuronal Function. Prog Neurobiol (2001) 64:51-68. doi: 10.1016/S0301-0082(00)00044-7

17. Sanders DB, Kelley T, Larson D. The Role of Nitric Oxide Synthase/Nitric Oxide in Vascular Smooth Muscle Control. Perfusion (2000) 15:97-104. doi: $10.1177 / 026765910001500203$ manuscript. All authors contributed to the article and approved the submitted version.

\section{FUNDING}

This work was supported by the National Natural Science Foundation of China (Grants Nos.32172726, 31772596) and the Open Project Program of State Key Laboratory of Hulless Barley and Yak. Germplasm Resources and Genetic Improvement (XZNKY-2021-C-014-K07). And the Key Research and Development Program of Jilin Province (20210202048NC, 20210202103NC).

18. Zaragoza C, Soria E, López E, Browning D, Balbín M, López-Otín C, et al. Activation of the Mitogen Activated Protein Kinase Extracellular SignalRegulated Kinase 1 and 2 by the Nitric Oxide-cGMP-cGMP-Dependent Protein Kinase Axis Regulates the Expression of Matrix Metalloproteinase 13 in Vascular Endothelial Cells. Mol Pharmacol (2002) 62:927-35. doi: 10.1124/mol.62.4.927

19. Grasselli F, Ponderato N, Basini G, Tamanini C. Nitric Oxide Synthase Expression and Nitric Oxide/Cyclic GMP Pathway in Swine Granulosa Cells. Domest Anim Endocrinol (2001) 20:241-52. doi: 10.1016/S0739-7240(01) 00096-0

20. Abán CE, Accialini PL, Etcheverry T, Leguizamón GF, Martinez NA, Farina MG. Crosstalk Between Nitric Oxide and Endocannabinoid Signaling Pathways in Normal and Pathological Placentation. Front Physiol (2018) 9:1699. doi: 10.3389/fphys.2018.01699

21. Constantin S, Reynolds D, Oh A, Pizano K, Wray S. Nitric Oxide Resets Kisspeptin-Excited GnRH Neurons via PIP2 Replenishment. Proc Natl Acad Sci (2021) 118(1):e2012339118. doi: 10.1073/pnas.2012339118

22. Watanobe H, Schiöth HB. Nitric Oxide Mediates Leptin-Induced Preovulatory Luteinizing Hormone and Prolactin Surges in Rats. Brain Res (2001) 923:193-7. doi: 10.1016/S0006-8993(01)03247-4

23. Li J, Zhang W, Zhu S, Shi F. Nitric Oxide Synthase Is Involved in Follicular Development via the PI3K/AKT/FoxO3a Pathway in Neonatal and Immature Rats. Animals (2020) 10:248. doi: 10.3390/ani10020248

24. Kong BWC, Vanhoutte PM, Man RYK, Leung SWS. 17ß-Estradiol Potentiates Endothelium-Dependent Nitric Oxide-and HyperpolarizationMediated Relaxations in Blood Vessels of Male But Not Female Apolipoprotein-E Deficient Mice. Vasc Pharmacol (2015) 71:166-73. doi: 10.1016/j.vph.2015.02.009

25. Gądek-Michalska A, Tadeusz J, Rachwalska P, Bugajski J. Cytokines, Prostaglandins and Nitric Oxide in the Regulation of Stress-Response Systems. Pharmacol Rep (2013) 65:1655-62. doi: 10.1016/S1734-1140(13) 71527-5

26. McBryde FD, Liu BH, Roloff EV, Kasparov S, Paton JFR. Hypothalamic Paraventricular Nucleus Neuronal Nitric Oxide Synthase Activity Is a Major Determinant of Renal Sympathetic Discharge in Conscious Wistar Rats. Exp Physiol (2018) 103:419-28. doi: 10.1113/EP086744

27. Buhimschi I, Ali M, Jain V, Chwalisz K, Garfield RE. Pregnancy: Differential Regulation of Nitric Oxide in the Rat Uterus and Cervix During Pregnancy and Labour. Hum Reprod (1996) 11:1755-66. doi: 10.1093/oxfordjournals. humrep.a019481

28. Kim H, Moon C, Ahn M, Lee Y, Kim H, Kim S, et al. Expression of Nitric Oxide Synthase Isoforms in the Porcine Ovary During Follicular Development. J Veterinary Sci (2005) 6(2):97-101. doi: 10.4142/ jvs.2005.6.2.97

29. Matsumi H, Yano T, Osuga Y, Kugu K, Tang X, Xu JP, et al. Regulation of Nitric Oxide Synthase to Promote Cytostasis in Ovarian Follicular Development. Biol Reprod (2000) 63:141-6. doi: 10.1095/biolreprod63.1.141

30. Matsumi H, Yano T, Koji T, Ogura T, Tsutsumi O, Taketani Y, et al Expression and Localization of Inducible Nitric Oxide Synthase in the Rat 
Ovary: A Possible Involvement of Nitric Oxide in the Follicular Development. Biochem Biophys Res Commun (1998) 243:67-72. doi: 10.1006/bbrc. 1997.8063

31. Takesue K, Tabata S, Sato F, Hattori M. Expression of Nitric Oxide Synthase3 in Porcine Oocytes Obtained at Different Follicular Development. J Reprod Dev (2003) 49:135-40. doi: 10.1262/jrd.49.135

32. Tao Y, Fu Z, Zhang M, Xia G, Yang J, Xie H. Immunohistochemical Localization of Inducible and Endothelial Nitric Oxide Synthase in Porcine Ovaries and Effects of NO on Antrum Formation and Oocyte Meiotic Maturation. Mol Cell Endocrinol (2004) 222:93-103. doi: 10.1016/ j.mce.2004.04.014

33. Nath P, Mukherjee U, Biswas S, Pal S, Das S, Ghosh S, et al. Expression of Nitric Oxide Synthase (NOS) in Anabas Testudineus Ovary and Participation of Nitric Oxide-Cyclic GMP Cascade in Maintenance of Meiotic Arrest. Mol Cell Endocrinol (2019) 496:110544. doi: 10.1016/ j.mce.2019.110544

34. Singh VK, Lal B. Immunolocalization of Nitric Oxide Synthase (NOS) Isoforms in Ovarian Follicles of the Catfish, Clarias Batrachus and Its Relation With Ovarian Activity. Gen Comp Endocrinol (2015) 220:98-102. doi: 10.1016/j.ygcen.2014.04.001

35. Nath P, Maitra S. Physiological Relevance of Nitric Oxide in Ovarian Functions: An Overview. Gen Comp Endocrinol (2019) 279:35-44. doi: 10.1016/j.ygcen.2018.09.008

36. Rosselli M, Keller RJ, Dubey RK. Role of Nitric Oxide in the Biology, Physiology and Pathophysiology of Reproduction. Hum Reprod Update (1998) 4:3-24. doi: 10.1093/humupd/4.1.3

37. Mitchell LM, Kennedy CR, Hartshorne GM. Expression of Nitric Oxide Synthase and Effect of Substrate Manipulation of the Nitric Oxide Pathway in Mouse Ovarian Follicles. Hum Reprod (2004) 19:30-40. doi: 10.1093/ humrep/deh032

38. Pires PRL, Santos NP, Adona PR, Natori MM, Schwarz KRL, de Bem THC, et al. Endothelial and Inducible Nitric Oxide Synthases in Oocytes of Cattle. Anim Reprod Sci (2009) 116:233-43. doi: 10.1016/j.anireprosci.2009.02.019

39. Ferrari AU, Radaelli A, Mori I, Mircoli L, Perlini S, Meregalli P, et al. Nitric Oxide-Dependent Vasodilation and the Regulation of Arterial Blood Pressure. J Cardiovasc Pharmacol (2001) 38:S19-22. doi: 10.1097/ 00005344-200111002-00006

40. Dubey PK, Tripathi V, Singh RP, Saikumar G, Nath A, Gade N, et al. Expression of Nitric Oxide Synthase Isoforms in Different Stages of Buffalo (Bubalus Bubalis) Ovarian Follicles: Effect of Nitric Oxide on In Vitro Development of Preantral Follicle. Theriogenology (2012) 77:280-91. doi: 10.1016/j.theriogenology.2011.08.002

41. Skarzynski DJ, Jaroszewski JJ, Bah MM, Deptula KM, Barszczewska B, Gawronska B, et al. Administration of a Nitric Oxide Synthase Inhibitor Counteracts Prostaglandin F2-Induced Luteolysis in Cattle. Biol Reprod (2003) 68:1674-81. doi: 10.1095/biolreprod.102.008573

42. Honaramooz A, Cook SJ, Beard AP, Bartlewski PM, Rawlings NC. Nitric Oxide Regulation of Gonadotrophin Secretion in Prepubertal Heifers1. J Neuroendocrinol (1999) 11:667-76. doi: 10.1046/j.1365-2826.1999.00366.x

43. Tian Y, Ding Y, Liu J, Heng D, Xu K, Liu W, et al. Nitric Oxide-Mediated Regulation of GLUT by T3 and Follicle-Stimulating Hormone in Rat Granulosa Cells. Endocrinology (2017) 158:1898-915. doi: 10.1210/en.2016-1864

44. Jablonka-Shariff A, Olson LM. Hormonal Regulation of Nitric Oxide Synthases and Their Cell-Specific Expression During Follicular Development in the Rat Ovary. Endocrinology (1997) 138:460-8. doi: 10.1210/endo.138.1.4884

45. Sengoku K, Takuma N, Horikawa M, Tsuchiya K, Komori H, Sharifa D, et al. Requirement of Nitric Oxide for Murine Oocyte Maturation, Embryo Development, and Trophoblast Outgrowth In Vitro. Mol Reprod Development: Incorporating Gamete Res (2001) 58:262-8. doi: 10.1002/ 1098-2795(200103)58:3<262::AID-MRD3>3.0.CO;2-8

46. Pinto CRF, Paccamonti DL, Eilts BE, Short CR, Gentry L, Thompson DL, et al. Evidence for a Nitric Oxide-Mediated Modulation of Equine Granulosa Cell Steroidogenesis. Theriogenology (2002) 58:579. doi: 10.1016/S0093691X(02)00759-8

47. Tao Y, Xie H, Hong H, Chen X, Jang J, Xia G. Effects of Nitric Oxide Synthase Inhibitors on Porcine Oocyte Meiotic Maturation. Zygote (2005) 13:1. doi: $10.1017 /$ S0967199404002953
48. Minge CE, Ryan NK, Hoek KHVD, Robker RL, Norman RJ. Troglitazone Regulates Peroxisome Proliferator-Activated Receptors and Inducible Nitric Oxide Synthase in Murine Ovarian Macrophages. Biol Reprod (2006) 74:153-60. doi: 10.1095/biolreprod.105.043729

49. Preti SC, Da Cunha V, Vassallo DV, Stefanon I. The Superoxide Dismutase Mimetic, Tempol, Reduces the Bioavailability of Nitric Oxide and Does Not Alter L-Name-Induced Hypertension in Rats. Basic Clin Pharmacol Toxicol (2005) 97:29-34. doi: 10.1111/j.1742-7843.2005.pto_97105.x

50. Chen Y-HJ, Tafoya M, Ngo A, LaPolt PS. Effects of Nitric Oxide and cGMP on Inhibin A and Inhibin Subunit mRNA Levels From Cultured Rat Granulosa Cells. Fertil Steril (2003) 79:687-93. doi: 10.1016/S0015-0282 (02)04823-9

51. Hess KA, Waltz SE, Toney-Earley K, Degen SJF. The Receptor Tyrosine Kinase Ron Is Expressed in the Mouse Ovary and Regulates Inducible Nitric Oxide Synthase Levels and Ovulation. Fertil Steril (2003) 80:747-54. doi: 10.1016/S0015-0282(03)00774-X

52. McCosh RB, Lopez JA, Szeligo BM, Bedenbaugh MN, Hileman SM, Coolen LM, et al. Evidence That Nitric Oxide Is Critical for LH Surge Generation in Female Sheep. Endocrinology (2020) 161(3):bqaa010. doi: 10.1210/endocr/ bqaa 010

53. Huang H-F, Wang B, Yang X-F, Luo Q, Sheng J-Z. Nitric Oxide Mediates Inhibitory Effect of Leptin on Insulin-Like Growth Factor I Augmentation of 17ß-Estradiol Production in Human Granulosa Cells. Biol Reprod (2005) 72:102-6. doi: 10.1095/biolreprod.104.032078

54. Zicari A, Centonze C, Realacci M, Buchetti B, Pietropolli A, Ticconi C. Estradiol 17- $\beta$ and Progesterone Modulate Inducible Nitric Oxide Synthase and High Mobility Group Box 1 Expression in Human Endometrium. Reprod Sci (2008) 15:559-66. doi: 10.1177/1933719107312560

55. Barnes MJ, Lapanowski K, Rafols JA, Lawson DM, Dunbar JC. Chronic Nitric Oxide Deficiency Is Associated With Altered Leutinizing Hormone and Follicle-Stimulating Hormone Release in Ovariectomized Rats1. Exp Biol Med (2002) 227:817-22. doi: 10.1177/153537020222700915

56. Barnes MJ, Lapanowski K, Rafols JA, Lawson DM, Dunbar JC. GnRH and Gonadotropin Release Is Decreased in Chronic Nitric Oxide Deficiency. Exp Biol Med (2001) 226:701-6. doi: 10.1177/153537020222600717

57. Matousek M, Carati C, Gannon B, Mitsube K, Brännström M. Changes in Intrafollicular Pressure in the Rat Ovary by Nitric Oxide and by Alteration of Systemic Blood Pressure. Eur J Obstetrics Gynecol Reprod Biol (2001) 98:4652. doi: 10.1016/S0301-2115(01)00338-4

58. Li J, Zhou W, Wang Y, Niu C. The Dual Role of cGMP in Oocyte Maturation of Zebrafish. Biochem Biophys Res Commun (2018) 499:998-1003. doi: 10.1016/j.bbrc.2018.04.037

59. Vignini A, Turi A, Giannubilo SR, Pescosolido D, Scognamiglio P, Zanconi $\mathrm{S}$, et al. Follicular Fluid Nitric Oxide (NO) Concentrations in Stimulated Cycles: The Relationship to Embryo Grading. Arch Gynecol Obstetrics (2008) 277:229-32. doi: 10.1007/s00404-007-0445-y

60. Yalçınkaya E, Çakıroğlu Y, Doğer E, Budak Ö, Çekmen M, Çalışkan E. Effect of Follicular Fluid NO, MDA and GSH Levels on In Vitro Fertilization Outcomes. J Turkish German Gynecol Assoc (2013) 14:136. doi: 10.5152/ jtgga.2013.53323

61. Barrionuevo MJ, Schwandt RA, Rao PS, Graham LB, Maisel LP, Yeko TR. Nitric Oxide (NO) and Interleukin-1beta (IL-1beta) in Follicular Fluid and Their Correlation With Fertilization and Embryo Cleavage. Am J Reprod Immunol (New York NY: 1989) (2000) 44:359-64. doi: 10.1111/j.87558920.2000.440607.x

62. Barroso G, Barrionuevo M, Rao P, Graham L, Danforth D, Huey S, et al. Vascular Endothelial Growth Factor, Nitric Oxide, and Leptin Follicular Fluid Levels Correlate Negatively With Embryo Quality in IVF Patients. Fertil Steril (1999) 72:1024-6. doi: 10.1016/S0015-0282(99)00442-2

63. Pande M, Das GK, Khan FA, Sarkar M, Pathak MC, Prasad JK, et al. Endometritis Impairs Luteal Development, Function, and Nitric Oxide and Ascorbic Acid Concentrations in Buffalo (Bubalus Bubalis). Trop Anim Health Production (2013) 45:805-10. doi: 10.1007/s11250-012-0292-0

64. Grazul-Bilska AT, Bass CS, Kaminski SL, Ebel KK, Leke E, Thammasiri J, et al. Effects of Plane of Nutrition and Arginine on Ovarian Follicles in NonPregnant Sheep: Cell Proliferation, and Expression of Endothelial Nitric Oxide and Its Receptor. Acta Histochemica (2019) 121:189-97. doi: 10.1016/ j.acthis.2018.12.009 
65. Jiang J-Y, Cheung CK, Wang Y, Tsang BK. Regulation of Cell Death and Cell Survival Gene Expression During Ovarian Follicular Development and Atresia. Front Biosci (2003) 8:222-37. doi: 10.2741/949

66. Dunnam RC, Hill MJ, Lawson DM, Dunbar JC. Ovarian Hormone Secretory Response to Gonadotropins and Nitric Oxide Following Chronic Nitric Oxide Deficiency in the Rat. Biol Reprod (1999) 60:959-63. doi: 10.1095/ biolreprod60.4.959

67. Chen Q, Yano T, Matsumi H, Osuga Y, Yano N, Xu J, et al. Cross-Talk Between Fas/Fas Ligand System and Nitric Oxide in the Pathway Subserving Granulosa Cell Apoptosis: A Possible Regulatory Mechanism for Ovarian Follicle Atresia. Endocrinology (2005) 146:808-15. doi: 10.1210/en.2004-0579

68. Basini G, Grasselli F, Ponderato N, Bussolati S, Tamanini C. Lipid Hydroperoxide and cGMP Are Not Involved in Nitric Oxide Inhibition of Steroidogenesis in Bovine Granulosa Cells. Reprod Fertil Dev (2000) 12:28995. doi: 10.1071/RD00089

69. Basini G, Grasselli F. Nitric Oxide in Follicle Development and Oocyte Competence. Reproduction (2015) 150:R1-9. doi: 10.1530/REP-14-0524

70. Francavilla F, Santucci R, Macerola B, Ruvolo G, Romano R. Nitric Oxide Synthase Inhibition in Human Sperm Affects Sperm-Oocyte Fusion But Not Zona Pellucida Binding. Biol Reprod (2000) 63:425-9. doi: 10.1095/ biolreprod63.2.425

71. Nishikimi A, Matsukawa T, Hoshino K, Ikeda S, Kira Y, Sato EF, et al. Localization of Nitric Oxide Synthase Activity in Unfertilized Oocytes and Fertilized Embryos During Preimplantation Development in Mice. Reproduction-Cambridge (2001) 122:957-63. doi: 10.1530/rep.0.1220957

72. Gouge RC, Marshburn P, Gordon BE, Nunley W, Huet-Hudson YM. Nitric Oxide as a Regulator of Embryonic Development. Biol Reprod (1998) 58:875-9. doi: 10.1095/biolreprod58.4.875

73. Staicu F-D, Canha-Gouveia A, Soriano-Úbeda C, Martínez-Soto JC, Adoamnei E, Chavarro JE, et al. Nitrite and Nitrate Levels in Follicular Fluid From Human Oocyte Donors Are Related to Ovarian Response and Embryo Quality. Front Cell Dev Biol (2021) 9. doi: 10.3389/fcell.2021.647002

74. Siamwala JH, Kumar P, Veeriah V, Muley A, Rajendran S, Konikkat S, et al. Nitric Oxide Reverses the Position of the Heart During Embryonic Development. Int J Mol Sci (2019) 20:1157. doi: 10.3390/ijms20051157

75. Abaffy P, Tomankova S, Naraine R, Kubista M, Sindelka R. The Role of Nitric Oxide During Embryonic Wound Healing. BMC Genomics (2019) 20:1-21. doi: 10.1186/s12864-019-6147-6

76. Yoon S, Choi K, Lee K. Nitric Oxide-Mediated Inhibition of Follicular Apoptosis Is Associated With HSP70 Induction and Bax Suppression. Mol Reprod Dev (2002) 61:504-10. doi: 10.1002/mrd.10033

77. Hu J, Ma S, Zou S, Li X, Cui P, Weijdegård B, et al. The Regulation of Nitric Oxide Synthase Isoform Expression in Mouse and Human Fallopian Tubes: Potential Insights for Ectopic Pregnancy. Int J Mol Sci (2015) 16:49-67. doi: 10.3390/ijms 16010049

78. Tsui K-H, Li H-Y, Cheng J-T, Sung Y-J, Yen M-S, Hsieh S-LE, et al. The Role of Nitric Oxide in the Outgrowth of Trophoblast Cells on Human Umbilical Vein Endothelial Cells. Taiwanese J Obstetrics Gynecol (2015) 54:227-31. doi: 10.1016/j.tjog.2013.11.010

79. Danilovich NA, Bartke A, Winters TA. Ovarian Follicle Apoptosis in Bovine Growth Hormone Transgenic Mice. Biol Reprod (2000) 62:103-7. doi: 10.1095/biolreprod62.1.103

80. Novaro V, Gonzalez E, Jawerbaum A, Rettori V, Canteros G, Gimeno MF. Nitric Oxide Synthase Regulation During Embryonic Implantation. Reprod Fertil Dev (1997) 9:557-64. doi: 10.1071/R97005

81. Purcell TL, Given R, Chwalisz K, Garfield RE. Nitric Oxide Synthase Distribution During Implantation in the Mouse. Mol Hum Reprod (1999) 5:467-75. doi: 10.1093/molehr/5.5.467

82. Biswas S, Kabir SN, Pal AK. The Role of Nitric Oxide in the Process of Implantation in Rats. Reproduction (1998) 114:157-61. doi: 10.1530/ jrf.0.1140157

83. Chwalisz K, Garfield RE. Role of Nitric Oxide in Implantation and Menstruation. Hum Reprod (2000) 15:96-111. doi: 10.1093/humrep/ 15.suppl_3.96

84. Dinara S, Sengoku K, Tamate K, Horikawa M, Ishikawa M. Effects of Supplementation With Free Radical Scavengers on the Survival and Fertilization Rates of Mouse Cryopreserved Oocytes. Hum Reprod (2001) 16:1976-81. doi: 10.1093/humrep/16.9.1976
85. Staicu F-D, Lopez-Úbeda R, Romero-Aguirregomezcorta J, Martínez-Soto JC, Matás C. Regulation of Boar Sperm Functionality by the Nitric Oxide Synthase/Nitric Oxide System. J Assisted Reprod Genet (2019) 36:1721-36. doi: 10.1007/s10815-019-01526-6

86. Banihani SA, Shatnawi RM. Aspirin Decreases Human Sperm Motility and Vitality, Chelates Seminal Calcium, But Insignificantly Reduces Seminal Nitric Oxide Production. Andrologia (2020) 52:e13776. doi: 10.1111/ and.13776

87. Wang J, He Q, Yan X, Cai Y, Chen J. Effect of Exogenous Nitric Oxide on Sperm Motility. vitro Biol Res (2014) 47:1-8. doi: 10.1186/0717-6287-47-44

88. Osycka-Salut C, Gervasi MG, Pereyra E, Cella M, Ribeiro ML, Franchi AM, et al. Anandamide Induces Sperm Release From Oviductal Epithelia Through Nitric Oxide Pathway in Bovines. PloS One (2012) 7:e30671. doi: 10.1371/journal.pone.0030671

89. Aquila S, Giordano F, Guido C, Rago V, Carpino A. Nitric Oxide Involvement in the Acrosome Reaction Triggered by Leptin in Pig Sperm. Reprod Biol Endocrinol (2011) 9:1-6. doi: 10.1186/1477-7827-9-133

90. Roohbakhsh A, Malaekeh-Nikouei B. Iranian Journal of Basic Medical Sciences, 2015 at a Glance. Iranian J basic Med Sci (2016) 19:1.

91. O'Bryan MK, Schlatt S, Gerdprasert O, Phillips DJ, de Kretser DM, Hedger MP. Inducible Nitric Oxide Synthase in the Rat Testis: Evidence for Potential Roles in Both Normal Function and Inflammation-Mediated Infertility. Biol Reprod (2000) 63:1285-93. doi: 10.1095/biolreprod63.5.1285

92. Kumar P, Chaturvedi CM. Correlation of Nitric Oxide (NO) Activity and Gonadal Function in Japanese Quail, Coturnix Coturnix Japonica Following Temporal Phase Relation of Serotonergic and Dopaminergic Oscillations. Anim Reprod Sci (2008) 106:48-64. doi: 10.1016/j.anireprosci.2007.03.025

93. Yang JZ, Ajonuma LC, Rowlands DK, Tsang LL, Ho LS, Lam SY, et al. The Role of Inducible Nitric Oxide Synthase in Gamete Interaction and Fertilization: A Comparative Study on Knockout Mice of Three NOS Isoforms. Cell Biol Int (2005) 29:785-91. doi: 10.1016/j.cellbi.2005.05.005

94. Soni Y, Softness K, Arora H, Ramasamy R. The Yin Yang Role of Nitric Oxide in Prostate Cancer. Am J Men's Health (2020) 14:1557988320903191. doi: $10.1177 / 1557988320903191$

95. Burnett AL, Musicki B. The Nitric Oxide Signaling Pathway in the Penis. Curr Pharm design (2005) 11:3987-94. doi: 10.2174/138161205774913381

96. Rochette L, Lorin J, Zeller M, Guilland J-C, Lorgis L, Cottin Y, et al. Nitric Oxide Synthase Inhibition and Oxidative Stress in Cardiovascular Diseases: Possible Therapeutic Targets? Pharmacol Ther (2013) 140:239-57. doi: 10.1016/j.pharmthera.2013.07.004

97. Simmonds MJ, Detterich JA, Connes P. Nitric Oxide, Vasodilation and the Red Blood Cell. Biorheology (2014) 51:121-34. doi: 10.3233/BIR-140653

98. Džoljić E, Grabatinić I, Kostić V. Why Is Nitric Oxide Important for Our Brain? Funct Neurol (2015) 30:159. doi: 10.11138/fneur/2015.30.3.159

99. Naghdi F, Gholamnezhad Z, Boskabady MH, Bakhshesh M. Muscarinic Receptors, Nitric Oxide Formation and Cyclooxygenase Pathway Involved in Tracheal Smooth Muscle Relaxant Effect of Hydro-Ethanolic Extract of Lavandula Angustifolia Flowers. Biomed Pharmacother (2018) 102:1221-8. doi: 10.1016/j.biopha.2018.04.004

100. Rallis D, Deierl A, Atreja G, Chaban B, Banerjee J. The Efficacy of Inhaled Nitric Oxide Treatment in Premature Infants With Acute Pulmonary Hypertension. Early Hum Dev (2018) 127:1-5. doi: 10.1016/j. earlhumdev.2018.09.004

101. Stewart L, Katial RK. Exhaled Nitric Oxide. Immunol Allergy Clinics (2012) 32:347-62. doi: 10.1016/j.iac.2012.06.005

102. Hoyte FCL, Gross LM, Katial RK. Exhaled Nitric Oxide: An Update. Immunol Allergy Clinics (2018) 38:573-85. doi: 10.1016/j.iac.2018.06.001

103. El-Haj L, Bestle MH. Nitric Oxide and Sepsis. Ugeskrift laeger (2017) 79(44): V0117008.

104. Banach M, Piskorska B, J Czuczwar S, K Borowicz K. Nitric Oxide, Epileptic Seizures, and Action of Antiepileptic Drugs. CNS Neurol Disorders-Drug Targets (Formerly Curr Drug Targets-CNS Neurol Disorders) (2011) 10:80819. doi: $10.2174 / 187152711798072347$

105. Goshi E, Zhou G, He Q. Nitric Oxide Detection Methods In Vitro and In Vivo. Med gas Res (2019) 9:192. doi: 10.4103/2045-9912.273957

106. Alimoradi H, Greish K, Gamble AB, Giles GI. Controlled Delivery of Nitric Oxide for Cancer Therapy. Pharm Nanotech (2019) 7:279-303. doi: 10.2174/ 2211738507666190429111306 
107. Adusumilli NC, Zhang D, Friedman JM, Friedman AJ. Harnessing Nitric Oxide for Preventing, Limiting and Treating the Severe Pulmonary Consequences of COVID-19. Nitric Oxide: Biol Chem (2020) 103:4-8. doi: 10.1016/j.niox.2020.07.003

108. Ricciardolo FLM, Bertolini F, Carriero V, Högman M. Nitric Oxide's Physiologic Effects and Potential as a Therapeutic Agent Against COVID19. J Breath Res (2020) 15:14001. doi: 10.1088/1752-7163/abc302

109. Malone-Povolny MJ, Maloney SE, Schoenfisch MH. Nitric Oxide Therapy for Diabetic Wound Healing. Adv Healthc Mater (2019) 8:1801210. doi: 10.1002/adhm.201801210

110. Yu-Jie MAO, Jian-Bing WU, Ze-Qiu Y, Zhang Y-H, Huang Z-J. Nitric Oxide Donating Anti-Glaucoma Drugs: Advances and Prospects. Chin J Nat Medic (2020) 18:275-83. doi: 10.1016/S1875-5364(20)30035-2

111. Bruand C, Meilhoc E. Nitric Oxide in Plants: Pro-or Anti-Senescence. J Exp Bot (2019) 70:4419-27. doi: 10.1093/jxb/erz117

112. Miyazaki Y, Ichinose F. Nitric Oxide in Post-Cardiac Arrest Syndrome. JCardiovasc Pharmacol (2020) 75:508-15. doi: 10.1097/FJC.0000000000000765

113. Yu B, Ichinose F, Bloch DB, Zapol WM. Inhaled Nitric Oxide. $\mathrm{Br} J$ Pharmacol (2019) 176:246-55. doi: 10.1111/bph.14512

114. Wallace JL. Nitric Oxide in the Gastrointestinal Tract: Opportunities for Drug Development. Br J Pharmacol (2019) 176:147-54. doi: 10.1111/bph.14527

115. McCarthy O, Moser O, Eckstein ML, Bain SC, Pitt J, Bracken R. Supplementary Nitric Oxide Donors and Exercise as Potential Means to Improve Vascular Health in People With Type 1 Diabetes: Yes to NO? Nutrients (2019) 11:1571. doi: 10.3390/nu11071571
116. Keshet R, Erez A. Arginine and the Metabolic Regulation of Nitric Oxide Synthesis in Cancer. Dis Models Mech (2018) 11:dmm033332. doi: 10.1242/ dmm.033332

Conflict of Interest: WB and YZ are members of the State Key Laboratory of Barley Yak Germplasm Resources and Genetics, not the Lhasa LTD. Here are their detailed units: State Key Laboratory of Hulless Barley and Yak Germplasm Resources and Genetic Improvement, Lhasa, Tibet 850002, China.

The remaining authors declare that the research was conducted in the absence of any commercial or financial relationships that could be construed as a potential conflict of interest.

Publisher's Note: All claims expressed in this article are solely those of the authors and do not necessarily represent those of their affiliated organizations, or those of the publisher, the editors and the reviewers. Any product that may be evaluated in this article, or claim that may be made by its manufacturer, is not guaranteed or endorsed by the publisher.

Copyright (c) 2021 Luo, Zhu, Basang, Wang, Li and Zhou. This is an open-access article distributed under the terms of the Creative Commons Attribution License (CC BY). The use, distribution or reproduction in other forums is permitted, provided the original author(s) and the copyright owner(s) are credited and that the original publication in this journal is cited, in accordance with accepted academic practice. No use, distribution or reproduction is permitted which does not comply with these terms. 